\title{
Penentuan Energi Dasar Atom Berilium (Be) Menggunakan Metode Variasional Dengan Dua Parameter
}

\author{
Nurlina*1, Fitriah Bidalo ${ }^{2}$, Z. Su'ud ${ }^{3}$ \\ ${ }^{1}$ Program Studi Pendidikan Fisika, Fakultas Keguruan dan Ilmu Pendidikan, Universitas Sulawesi Barat, \\ Jl. Letjen Hertasning, Majene 91412, Sulawesi Barat, Indonesia \\ ${ }^{2}$ Bidang Pengendalian, Pencemaran, dan Kerusakan Lingkungan Hidup, Dinas Lingkungan Hidup Kabupaten \\ Banggai Kepulauan \\ ${ }^{3}$ Kelompok Keilmuan Fisika Nuklir dan Biofisika, Jurusan Fisika, Fakultas Matematika dan Ilmu \\ Pengetahuan Alam, Institut Teknologi Bandung, Jl. Ganesha No. 10 Bandung 40132, Indonesia \\ e-mail: *11nurlina@unsulbar.ac.id, ${ }^{2}$ fitriahbidalo@gmail.com, ${ }^{3}$ szaki@fi.itb.ac.id
}

\begin{abstract}
Abstrak
Studi ini bertujuan untuk menentukan energi dasar atom Berilium (Be) menggunakan metode variasional dengan dua parameter. Perhitungan energi dasar atom Berilium dilakukan dengan meminimalisasi fungsi gelombang untuk memperoleh nilai parameter variasi yang efektif. Dengan menggunakan metode variasional dua parameter, diperoleh energi keadaan dasar atom Berilium sebesar 394,066 eV (1,26\% dari energi referensi) dengan nilai parameter $Z_{1}=3,65837$ dan $Z_{2}=2$, 10137. Dari hasil tersebut, terlihat bahwa nilai energi keadaan dasar yang diperoleh cukup mendekati nilai energi referensi. Hal ini mengindikasikan bahwa metode variasional dua parameter cukup baik dalam menjelaskan sifat-sifat energi keadaan dasar suatu atom.
\end{abstract}

Kata kunci: atom Berilium, energi keadaan dasar, metode variasional

\section{PENDAHULUAN}

Salah satu kajian penting dalam studi tentang atom adalah penentuan energi pada keadaan dasarnya. Ada banyak metode yang dapat digunakan untuk menentukan energi keadaan dasar suatu atom dan pada dasarnya dapat dilakukan dengan cara menyelesaikan persamaan Schrodinger-nya. Namun hal tersebut cenderung sangat sulit untuk kasus atom-atom yang berelektron banyak karena melibatkan persamaan yang cukup rumit (Griffiths 1994).

Metode variasional adalah suatu cara aproksimasi yang cukup baik untuk menentukan energi tingkat dasar suatu atom. Metode variasional adalah salah satu metode utama yang digunakan untuk memperoleh perkiraan tingkat energi dan fungsi gelombang suatu sistem yang tidak memiliki solusi analitik yang tepat (Tambasco 1997). Dalam mengkaji sifat-sifat atom, terutama yang berkaitan dengan energi keadaan dasarnya, selain menggunakan metode Hartree Fock dan Density Function Theory (DFT), metode variasional juga terbukti cukup baik dalam menjelaskan keadaan dasar dari suatu atom (Griffiths 1994; Puchalski and Pachucki 2006). Selain itu, metode ini juga dapat digunakan untuk menentukan keadaan tereksitasi suatu atom menggunakan prinsip orthogonalitas dari solusi persamaan Schrodinger (Piela 2014; Rahman and Utami 2019).

Metode variasional dilakukan untuk menemukan pendekatan keadaan eigen energi terendah atau energi keadaan dasar. Dasar metode variasi ini adalah memilih sebuah fungsi gelombang yang tergantung pada satu atau lebih parameter variasi dan menemukan nilai-nilai parameter ini dengan nilai ekspektasi energi serendah mungkin. Penggunaan metode ini sangat membantu dalam kemudahan perhitungan, mengurangi kompleksitas perhitungan dan memberikan batas error yang relatif kecil (Rioux 1999). Metode variasional ini memiliki kesetaraan tertentu dengan metode perturbasi. Namun metode variasional lebih menguntungkan dalam penerapannya pada sistem partikel jamak seperti atom Berilium, khususnya untuk penentuan energi dan

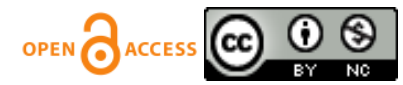


keadaan tingkat dasar, yang dapat diperbaiki ketelitiannya secara iteratif. Perluasannya untuk perhitungan keadaan eksitasi juga dapat dilakukan dengan cara interaksi konfigurasi.

Dalam studi ini, perhitungan energi dasar menggunakan atom Berilium, karena secara teori konfigurasi elektron atom Berilium adalah $1 s^{2}, 2 s^{2}$., memiliki dua elektron di bagian dalam (Shell $K$ ) dan dua elektron di kulit luar (Shell L) sehingga konfigurasi atom Berilium ini cukup menarik untuk dikaji, sebagaimana yang telah dilakukan oleh peneliti sebelumnya (Wu and Meng 2018; Y. Yulianto, R. Ramdani, M.S. Abidin 2017). Tujuan dari studi ini adalah untuk menghitung energi keadaan dasar atom Berilium menggunakan metode variasional dengan dua parameter variasi.

\section{METODE PENELITIAN}

Secara ringkas, prosedur penerapan metode variasional dapat dinyatakan dalam empat langkah pokok yaitu (1) menentukan Hamiltonian sistem yang ditinjau; (2) memilih fungsi coba (trial function) dengan memasukkan parameter tertentu sebagai parameter variasi; (3) menentukan fungsional yang berupa elemen matriks diagonal; dan (4) minimasi Hamiltonian sistem terhadap fungsi coba atau parameter variasi bersangkutan.

\subsection{Penentuan Hamiltonian Sistem} sebagai,

Operator Hamiltonian (non-relativistik) untuk atom berelektron lebih dari satu dapat dinyatakan

$$
H=\sum_{i=1}^{4}\left(-\frac{1}{2} \nabla_{r_{i}}^{2}-\frac{Z}{r_{i}}\right)+\sum_{i<j=1}^{4} \frac{1}{r_{i j}}
$$

dengan $Z$ adalah nomor atom yang diteliti (B.H. Bransden 1983; Eisberg R. 1985; Wu and Meng 2018). Untuk atom Berilium, operator Hamiltonian yang digunakan adalah

$$
H=-\frac{\hbar^{2}}{2 m}\left(\nabla_{1}+\nabla_{2}+\nabla_{3}+\nabla_{4}\right)-\frac{e^{2}}{4 \pi \varepsilon_{0}}\left(\frac{4}{r_{1}}+\frac{4}{r_{2}}+\frac{4}{r_{3}}+\frac{4}{r_{4}}\right)+\frac{e^{2}}{4 \pi \varepsilon_{0}}\left(\frac{1}{r_{12}}+\frac{1}{r_{13}}+\frac{1}{r_{14}}+\frac{1}{r_{23}}+\frac{1}{r_{24}}+\frac{1}{r_{34}}\right)
$$

dengan $\hbar$ adalah konstanta Planck, $m$ adalah massa elektron, $e$ adalah muatan elektron, $r$ adalah jarak elektron terhadap inti atom (untuk yang berindeks tunggal $r_{1}, r_{2}, r_{3}, r_{4}$ ) dan jarak antar-elektron (untuk yang berindeks ganda $\left.r_{12}, r_{13}, r_{14}, r_{23}, r_{24}, r_{34}\right)$. Empat suku pertama merupakan energi kinetik elektron, empat suku kedua adalah energi potensial yang terjadi akibat interaksi elektron dengan inti atom, dan enam suku terakhir adalah suku interaksi antar-elektron (Baretti, 2019).

\subsection{Pemilihan Fungsi Coba}

Untuk memilih fungsi coba $|\psi\rangle$, suku interaksi antar elektron $1 / r_{i j}$ diabaikan, tidak memiliki pengaruh yang berarti (sekedar merupakan gangguan/koreksi), sehingga Hamiltonian sistem menjadi,

$$
H^{(0)}=-\frac{\hbar^{2}}{2 m}\left(\nabla_{1}+\nabla_{2}+\nabla_{3}+\nabla_{4}\right)-\frac{e^{2}}{4 \pi \varepsilon_{0}}\left(\frac{4}{r_{1}}+\frac{4}{r_{2}}+\frac{4}{r_{3}}+\frac{4}{r_{4}}\right)
$$

Fungsi gelombang yang digunakan adalah fungsi gelombang atom Hidrogen yang dinyatakan sebagai,

$$
\begin{gathered}
\psi_{100}(r)=\sqrt{\frac{Z_{1}^{3}}{\pi a^{3}} e^{\frac{-Z_{1} r}{a}}} \\
\psi_{200}(r)=\sqrt{\frac{Z_{2}^{3}}{32 \pi a^{3}}}\left(2-\frac{Z_{2} r}{a}\right) e^{\frac{-Z_{2} r}{a}}
\end{gathered}
$$

dimana $Z_{1}$ dan $Z_{2}$ adalah parameter variasi dan $a$ adalah jari-jari atom Bohr (Eisberg R. 1985). 


\subsection{Penentuan Energi Atom Berilium}

Penentuan energi dasar atom Berilium dilakukan dengan menjumlahkan energi atom Berilium tanpa koreksi interaksi antar-elektron dan energi atom Berilium dengan koreksi interaksi antar-elektron.

\subsubsection{Energi Atom Berilium Tanpa Interaksi Antar-Elektron}

Karena tidak mengandung suku interaksi antar-elektron, maka penyelesaian persamaan eigen $H^{(0)}$ dilakukan secara terpisah untuk masing-masing variabel (separasi variabel) (Griffiths 1994). Dengan menggunakan separasi variabel, diperoleh nilai-nilai eigen untuk masing-masing elektron sebagai berikut:

$$
\begin{aligned}
& \left(-\frac{\hbar^{2}}{2 m} \nabla_{1}^{2}-\frac{e^{2}}{4 \pi \varepsilon_{0}} \frac{Z_{1}}{r_{1}}\right) \psi_{1}=E_{1} \psi_{1} \\
& \left(-\frac{\hbar^{2}}{2 m} \nabla_{2}^{2}-\frac{e^{2}}{4 \pi \varepsilon_{0}} \frac{Z_{1}}{r_{2}}\right) \psi_{2}=E_{2} \psi_{2} \\
& \left(-\frac{\hbar^{2}}{2 m} \nabla_{3}^{2}-\frac{e^{2}}{4 \pi \varepsilon_{0}} \frac{Z_{2}}{r_{3}}\right) \psi_{3}=E_{3} \psi_{3} \\
& \left(-\frac{\hbar^{2}}{2 m} \nabla_{4}^{2}-\frac{e^{2}}{4 \pi \varepsilon_{0}} \frac{Z_{2}}{r_{4}}\right) \psi_{4}=E_{4} \psi_{4}
\end{aligned}
$$

Dimana nilai ekspektasi energi

$$
\langle E\rangle=E_{1}+E_{2}+E_{3}+E_{4}
$$

Dengan memecahkan persamaan diatas, diperoleh

$$
\begin{gathered}
E_{1}=E_{2}=Z_{1}^{2} E_{0} \\
E_{3}=E_{4}=Z_{2}^{2} \frac{E_{0}}{4} \\
E_{1}+E_{2}+E_{3}+E_{4}=2 Z_{1}^{2} E_{0}+2 Z_{2}^{2} \frac{E_{0}}{4}
\end{gathered}
$$

Dimana $E_{0}$ adalah energi dasar atom Hidrogen (-13,6 eV). Dari keempat energi di atas, maka nilai energi ekpektasi atom Berilium tanpa interaksi antar-elektron dapat dituliskan sebagai

$$
\langle E\rangle=2 E_{0}\left(Z_{1}^{2}+\frac{Z_{2}^{2}}{4}\right)
$$

\subsubsection{Energi Atom Berilium Dengan Interaksi Antar Elektron}

Pengaruh interaksi $1 / r_{i j}$ pada keadaan dasar dapat diungkapkan sebagai efek screening yang mengubah parameter $Z_{1}$ dan $Z_{2}$ menjadi harga efektifnya. Untuk energi interaksi antar elektron, dapat dipecahkan dengan menggunakan teori gangguan (perturbation theory) dengan menyelesaikan fungsi coba yang yang telah ditetapkan sebelumnya (Griffiths 1994),

$$
\begin{gathered}
\left\langle V_{e e}\right\rangle=\langle\psi|H| \psi\rangle \\
\left\langle V_{e e}\right\rangle=\left\langle V_{12}\right\rangle+\left\langle V_{13}\right\rangle+\left\langle V_{14}\right\rangle+\left\langle V_{23}\right\rangle+\left\langle V_{24}\right\rangle+\left\langle V_{34}\right\rangle
\end{gathered}
$$

Interaksi elektron 1 dengan elektron $2\left(V_{12}\right)$, diperoleh energi sebesar

$$
\left\langle V_{12}\right\rangle=-\frac{5}{4} Z_{1} E_{0}
$$

Interaksi elektron 1 dengan elektron 3 yang besarnya sama dengan interaksi elektron 1 dengan elektron 4 , elektron 2 dengan elektron 3, dan elektron 2 dengan elektron $4\left(V_{13}=V_{14}=V_{23}=V_{24}\right)$, diperoleh energi sebesar 
https://jurnal.unsulbar.ac.id/index.php/saintifik

$$
\left\langle V_{13}\right\rangle=\frac{1}{2} Z_{1}^{3} Z_{2}^{3} E_{0}\left\{\frac{24}{Z_{2}\left(2 Z_{1}+Z_{2}\right)^{4}}+\frac{24}{Z_{2}^{2}\left(2 Z_{1}+Z_{2}\right)^{3}}+\frac{16}{Z_{2}^{3}\left(2 Z_{1}+Z_{2}\right)^{2}}+\frac{48}{\left(2 Z_{1}+Z_{2}\right)^{5}}-\frac{4}{Z_{1}^{2} Z_{2}^{3}}\right\}
$$

Interaksi elektron 3 dengan elektron $4\left(V_{34}\right)$, diperoleh energi sebesar,

$$
\left\langle V_{34}\right\rangle=-\frac{77}{256} Z_{2} E_{0}
$$

Dengan menggabungkan semua hasil di atas untuk energi atom Berilium dengan interaksi antar-elektron, diperoleh,

$$
\begin{gathered}
E_{T}=\left\langle V_{12}\right\rangle+\left\langle V_{13}\right\rangle+\left\langle V_{14}\right\rangle+\left\langle V_{23}\right\rangle+\left\langle V_{24}\right\rangle+\left\langle V_{34}\right\rangle \\
E_{T}=-\frac{5}{4} Z_{1} E_{0}-2 Z_{1}^{3} Z_{2}^{3} E_{0}\left\{\begin{array}{l}
-\frac{24}{Z_{2}\left(2 Z_{1}+Z_{2}\right)^{4}}-\frac{24}{Z_{2}^{2}\left(2 Z_{1}+Z_{2}\right)^{3}} \\
-\frac{16}{Z_{2}^{3}\left(2 Z_{1}+Z_{2}\right)^{2}}-\frac{48}{\left(2 Z_{1}+Z_{2}\right)^{5}}+\frac{4 a^{5}}{Z_{1}^{2} Z_{2}^{3}}
\end{array}\right\}-\frac{154}{512} Z_{2} E_{0}
\end{gathered}
$$

\subsection{Minimasi $\langle\boldsymbol{H}\rangle$ Terhadap Parameter Variasi}

Langkah selanjutnya adalah menghitung energi sistem dengan memvariasikan parameter $Z_{1}$ dan $Z_{2}$. Hamiltonian pada kondisi ini dituliskan,

$$
\begin{gathered}
H=\sum_{i=1}^{4}\left(-\frac{1}{2} \nabla_{r_{i}}^{2}-\frac{Z}{r_{i}}\right)+\sum_{i<j=1}^{4} \frac{1}{r_{i j}} \\
H=-\frac{\hbar^{2}}{2 m}\left(\nabla_{1}^{2}+\nabla_{2}^{2}+\nabla_{3}^{2}+\nabla_{4}^{2}\right)-\frac{e^{2}}{4 \pi \varepsilon_{0}}\left(\frac{Z_{1}}{r_{1}}+\frac{Z_{1}}{r_{2}}+\frac{Z_{2}}{r_{3}}+\frac{Z_{2}}{r_{4}}\right)+\frac{e^{2}}{4 \pi \varepsilon_{0}}\left(\frac{Z_{1}-4}{r_{1}}+\frac{Z_{1}-4}{r_{2}}+\frac{Z_{2}-4}{r_{3}}+\frac{Z_{2}-4}{r_{4}}\right) \\
+\frac{e^{2}}{4 \pi \varepsilon_{0}}\left(\frac{1}{r_{12}}+\frac{1}{r_{13}}+\frac{1}{r_{14}}+\frac{1}{r_{23}}+\frac{1}{r_{24}}+\frac{1}{r_{34}}\right)
\end{gathered}
$$

Berdasarkan hasil-hasil di atas, dilakukan penyederhanaan sedemikian rupa sehingga diperoleh rumusan,

$$
\langle H\rangle=E_{0}\left\{\begin{array}{l}
-2 Z_{1}^{2}-\frac{Z_{2}^{2}}{2}+16 Z_{1}+4 Z_{2}-\frac{5}{4} Z_{1}-\frac{77}{256} Z_{2}+\frac{48 Z_{1}^{3} Z_{2}^{2}}{\left(2 Z_{1}+Z_{2}\right)^{4}}+\frac{48 Z_{1}^{3} Z_{2}}{\left(2 Z_{1}+Z_{2}\right)^{3}} \\
+\frac{32 Z_{1}^{3}}{\left(2 Z_{1}+Z_{2}\right)^{2}}+\frac{96 Z_{1}^{3} Z_{2}^{3}}{\left(2 Z_{1}+Z_{2}\right)^{5}}-8 Z_{1}
\end{array}\right\}
$$

Berdasarkan metode variasional, kuantitas di atas melewati nilai energi keadaan dasar untuk parameter apapun. Aproksimasi atau fungsi coba yang terbaik adalah yang menghasilkan $\langle H\rangle$ yang paling kecil. Untuk itu, dilakukan minimasi $\langle H\rangle$ terhadap parameter $Z_{1}$ dan $Z_{2}$.

Hasil optimasi dengan menggunakan program MatLab menghasilkan nilai parameter $Z_{1}=3,65837$ dan $Z_{2}=2,10137$. Harga parameter variasi $Z_{1}$ dan $Z_{2}$. yang lebih kecil dari angka 4 (jumlah muatan inti) mengungkapkan efek perisai (screening) yang lazim dijumpai dalam atom berelektron jamak. Dengan memasukkan nilai ini untuk parameter variasi $Z_{1}$ dan $Z_{2}$. ke dalam $\langle H\rangle$, diperoleh $E_{\min }=-394,066 \mathrm{eV}$.

\section{HASIL DAN PEMBAHASAN}

Dalam studi ini, energi atom Berilium yang dijadikan referensi merupakan hasil yang diperoleh oleh (B.H. Bransden 1983) yaitu sebesar $-399,110 \mathrm{eV}$. Dari hasil perhitungan, diperoleh nilai parameter variasi sebesar $Z_{1}=3,65837$ dan $Z_{2}=2,10137$ dengan nilai energi yang dihasilkan sebesar $-394,066 \mathrm{eV}$. Hasil 
https://jurnal.unsulbar.ac.id/index.php/saintifik

perhitungan yang diperoleh sangat mendekati nilai energi referensi (1,26\% dari energi referensi). Adapun hasil perhitungan untuk masing-masing energi dapat dilihat pada Tabel 1 dan perbandingan hasil perhitungan energi keadaan dasar atom Berilium untuk beberapa referensi dapat dilihat pada Tabel 2.

Tabel 1. Hasil Perhitungan Energi Keadaan Dasar untuk Tiap Suku Energi Atom Berilium

\begin{tabular}{|c|c|}
\hline Parameter & Nilai Energi (eV) \\
\hline$E$ tanpa interaksi antar elektron & $-544,000$ \\
\hline$\left\langle V_{12}\right\rangle$ & 68,000 \\
\hline$\left\langle V_{13}\right\rangle=\left\langle V_{14}\right\rangle=\left\langle V_{23}\right\rangle=\left\langle V_{24}\right\rangle$ & 22,838 \\
\hline$\left\langle V_{34}\right\rangle$ & 16,362 \\
\hline$\left\langle V_{e e}\right\rangle$ & 175,714 \\
\hline$E_{\text {variasional }}(1$ parameter $)$ & $-382,486$ \\
\hline$E_{\text {variasional }}(2$ parameter $)$ & $-394,066$ \\
\hline
\end{tabular}

Tabel 2. Perbandingan Hasil Perhitungan Energi Keadaan Dasar Atom Berilium

\begin{tabular}{|l|c|c|c|c|}
\hline \multicolumn{1}{|c|}{ Referensi } & Tahun & Metode & \multicolumn{2}{c|}{ Energi } \\
\cline { 3 - 5 } (B.H. Bransden 1983) & 1983 & $\begin{array}{c}\text { Hartree-Fock } \\
\text { Eksak* }\end{array}$ & $\begin{array}{l}-14,573 \\
-14,667\end{array}$ & $\begin{array}{c}-396,552 \\
-399,110\end{array}$ \\
\hline (Tambasco 1997) & 1997 & Variasional & $-14,325$ & $-389,800$ \\
\hline $\begin{array}{l}\text { (Puchalski, Komasa, and } \\
\text { Pachucki 2013) }\end{array}$ & 2013 & Quantum Electrodynamics (QED) & $-14,667$ & $-399,122$ \\
\hline (Sims and Hagstrom 1971) & 1971 & $\begin{array}{c}\text { Combined Configuration- } \\
\text { Interaction-Hyllearaas-Type } \\
\text { Wave }\end{array}$ & $-14,666$ & $-399,091$ \\
\hline $\begin{array}{l}\text { (Ariful Kabir and Halder } \\
\text { 2015) }\end{array}$ & 2015 & $\begin{array}{c}\text { Variational Monte Carlo } \text { (VMC) } \\
\text { Method }\end{array}$ & $-14,667$ & $-399,122$ \\
\hline (Wu and Meng 2018) & 2018 & Perturbation Method & $-14,698$ & $-399,962$ \\
\hline (Machín n.d.) & 2013 & $\begin{array}{c}\text { Variasional (1 parameter) } \\
\text { Variasional (2 parameter) }\end{array}$ & $\begin{array}{l}-14,200 \\
-14,640\end{array}$ & $-386,402$ \\
\hline Studi ini & 2019 & $\begin{array}{c}\text { Variasional (1 parameter) } \\
\text { Variasional (2 parameter) }\end{array}$ & $\begin{array}{l}-14,056 \\
-14,481\end{array}$ & $-382,486$ \\
\hline
\end{tabular}

*dijadikan sebagai energi referensi

\section{KESIMPULAN}

Telah dilakukan perhitungan untuk menentukan energi dasar atom Berilium menggunakan metode variasional dengan dua parameter. Fungsi coba yang digunakan adalah fungsi gelombang pada atom Hidrogen. Dari hasil perhitungan, diperoleh energi dasar atom Berilium sebesar -394,066 eV. Hasil ini cukup baik karena perbedaan nilai yang diperoleh relatif kecil jika dibandingkan dengan nilai energi referensi yaitu sebesar $1,26 \%$, dimana nilai energi referensi yaitu sebesar $-399,110 \mathrm{eV}$. Hal ini menunjukkan bahwa metode variasional dengan dua parameter sangat cocok dalam menjelaskan sifat-sifat keadaan dasar suatu atom, khususnya yang berkaitan dengan energi keadaan dasar. Persentase perbedaan ini juga dapat diperkecil dengan menghitung koreksi relativistik, koreksi spin elektron, dan koreksi elektrodinamika kuantumnya pada perhitungan energinya. 
https://jurnal.unsulbar.ac.id/index.php/saintifik

\section{DAFTAR PUSTAKA}

Ariful Kabir, K. M. and Amal Halder. 2015. "Estimation of Beryllium Ground State Energy by Monte Carlo Simulation." AIP Conference Proceedings 1-7.

B.H. Bransden, C. J. Joachain. 1983. The Physics of Atoms and Molecules. First Edit. New York: John Wiley \& Sons, Inc., New York.

Eisberg R., Resnick R. 1985. Quantum Physics of Atoms, Molecules, Solids, Nuclei, and Particles. John Wiley \& Sons, Inc., New York.

Griffiths, David J. 1994. Introduction to Quantum Mechanics. New Jersey: Prentice Hall.

Machín, Reinaldo Baretti. n.d. "Chapter 10-b Ground State Energi." Retrieved (http://www.uprh.edu/rbaretti/LQMch11.htm). Diakses tanggal 15 Desember 2019.

Piela, Lucjan. 2014. "Two Fundamental Approximate Methods.” Pp. 231-56 in Ideas of Quantum Chemistry. Elsevier.

Puchalski, Mariusz, Jacek Komasa, and Krzysztof Pachucki. 2013. "Testing Quantum Electrodynamics in the Lowest Singlet States of the Beryllium Atom." Physical Review A - Atomic, Molecular, and Optical Physics 87(3).

Puchalski, Mariusz and Krzysztof Pachucki. 2006. "Ground-State Wave Function and Energy of the Lithium Atom." Physical Review A - Atomic, Molecular, and Optical Physics 73(2).

Rahman, Irsan and Fisca Dian Utami. 2019. "Penentuan Energi Dasar Atom Boron Dengan Menggunakan Metode Variasonal Satu Parameter.” 2(62).

Rioux, Frank. 1999. "Atomic Variational Calculations: Hydrogen to Boron.” The Chemical Educator 4(2):4043.

Sims, James S. and Stanley Hagstrom. 1971. "Combined Configuration-Interaction-Hylleraas-Type WaveFunction Study of the Ground State of the Beryllium Atom." Physical Review A 4(3):908-16.

Tambasco, M. 1997. "Variational Calculations For The Lithium Isoelectronic Sequence." University of Windsor.

Wu, Feng and Lijuan Meng. 2018. "Ground-State Energy of Beryllium Atom with Parameter Perturbation Method." Chinese Physics B 27(9):1-5.

Y. Yulianto, R. Ramdani, M.S. Abidin, Z. Su'ud. 2017. "Perhitungan Energi Ground State Atom Berilium Dengan Menggunakan Metode Variasional." Prosiding SKF 2017 169-73. 